01

\title{
PENGEMBANGAN POTENSI DESTINASI DESA WISATA MENGGUNAKAN INDEKS PEMBANGUNAN DESA DI BALESARI KECAMATAN WINDUSARI KABUPATEN MAGELANG
}

\author{
Bambang Kuncorol, Joko Tri Nugrahal, Retno Dewi Pramodia Ahsani3 . \\ IProgram Studi Ilmu Administrasi Negara, Fakultas Ilmu Sosial dan Ilmu Politik, Universitas \\ Tidar, bkun@ymail.com \\ 2Program Studi Ilmu Administrasi Negara, Fakultas Ilmu Sosial dan Ilmu Politik, Universitas \\ Tidar, jokotri.nugraha@gmail.com \\ Alamat email setiap penulis; dapat ditambah nomor hp \\ 3Program Studi Ilmu Administrasi Negara, Fakultas Ilmu Sosial dan Ilmu Politik, Universitas \\ Tidar,pramodiaahsani@gmail.com
}

\begin{abstract}
Abstrak
Di berlakukannya UU No. 6 Tahun 2014 tentang Desa dapat menjadi solusi terhadap permasalahan kesenjangan antara kota dan desa. Balesari termasuk salah satu desa di Kecamatan Windusari yang mempunyai luas 387 ha atau sekitar 3,34 persen dari luas Kecamatan Windusari. Penduduk Balesari berjumlah 2.788 jiwa. Sebanyak 1.421 berjenis kelamin laki-laki, sedangkan sisanya 1.367 berjenis kelamin perempuan. Tujuan penelitian ini adalah: (1) Menganalisis potensi di Desa Balesari dengan mendasarkan pada variabel indeks pembangunan desa dan; (2) Menyusun rekomendasi kebijakan sebagai upaya mewujudkan desa wisata Balesari dan kesejahteraan masyarakat. Pendekatan yang digunakan adalah studi kasus dengan teknik analisis model interaktif. Lokasi penelitian di Desa Balesari. Teknik pengumpulan data melalui wawancara serta observasi. Penelitian ini mempunyai arti yang sangat penting karena mempunyai kontribusi bagi penemuan akar masalah belum optimalnya pembangunan kawasan perdesaan di Indonesia. Hasil penelitian di lapangan menunjukkan hasil: (1) Penghitungan potensi desa Balesari menggunakan Indeks Pembangunan Desa sebesar 48,72119 artinya desa yang mempunyai ketersediaan dan akses terhadap pelayanan dasar, infrastruktur, aksesibilitas atau transportasi, pelayanan publik dan penyelenggaraan pemerintahan yang masih minim; (2) Kebijakan pemerintah daerah dalam mengontrol pengembangan wisata di Desa Balesari belum ada; (3) Kegiatan masyarakat dalam berkebun salak serta memelihara ternak dapat dikemas menjadi salah satu atraksi wisata.
\end{abstract}

Kata kunci: balesari, desa wisata, indeks pembangunan desa 


\begin{abstract}
Enacted Law No. 6 of 2014 concerning Villages can be a solution to the problem of disparity between cities and villages. Balesari is one of the villages in Windusari District which has an area of 387 ha or about 3.34 percent of the area of Windusari District. The population of Balesari is 2,788 people. A total of 1,421 were male, while the remaining 1,367 were female. The objectives of this study are: (1) Analyzing the potential in Balesari Village based on the village development index variable and; (2) Prepare policy recommendations as an effort to realize Balesari tourism village and community welfare. The approach used is a case study with interactive model analysis techniques. Research location in Balesari Village. The technique of collecting data through interviews and observation. This research has a very important meaning because it has a contribution to the discovery of the root cause of the problem of not optimal development of rural areas in Indonesia. The results of the research in the field show the results: (1) Calculation of Balesari village potential using the Village Development Index of 48.72119 means that villages have availability and access to basic services, infrastructure, accessibility or transportation, public services and minimal government administration; (2) Local government policies in controlling tourism development in Balesari Village do not yet exist; (3) Community activities in zalacca gardening and raising livestock can be packaged as one of the tourist attractions.
\end{abstract}

Key words: balesari, village tourism, village development index 


\section{Pendahuluan}

Pembangunan desa dan kawasan perdesaan secara komprehensif merupakan faktor penting bagi pembangunan daerah, pengentasan kemiskinan, dan pengurangan kesenjangan antarwilayah. Perkembangan jumlah desa di Indonesia meningkat pesat, dari 72.944 desa pada tahun 2012 menjadi 74.093 desa tahun 2014. Sayangnya jumlah yang selalu meningkat ini tidak diikuti dengan peningkatan kesejahteraan masyarakat. Keterisolasian wilayah karena keterbatasan akses, baik transportasi, telekomunikasi, pendidikan, kesehatan, maupun permukiman, terutama di desa-desa di kawasan perbatasan, daerah tertinggal, dan pulau-pulau kecil terluar, menjadi penyebab tingginya tingkat kemiskinan di desa.

Kesenjangan ini pada akhirnya menimbulkan permasalahan yang dalam konteks makro sangat merugikan proses pembangunan yang ingin dicapai. Ketidakseimbangan pembangunan antarwilayah seringkali terjadi akibat terpusatnya distribusi dan alokasi pemanfaatan sumberdaya yang berlebihan pada wilayah tertentu yang menjadi pusat-pusat pertumbuhan, sehingga menyebabkan makin lemahnya kawasan hinterland. Hal ini akan dapat menciptakan inefisiensi dan tidak optimalnya sistem ekonomi bahkan sangat berpotensi menyebabkan konflik sosial.
Selanjutnya kemiskinan di wilayah pinggiran/perdesaan akhirnya mendorong terjadinya migrasi penduduk ke perkotaan, sehingga kota dan pusat-pusat pertumbuhan menjadi melemah, dan inefisien dalam memberikan pelayanan terhadap masyarakat serta timbulnya masalah sosial, ekonomi, dan lingkungan yang semakin kompleks dan sulit diatasi. Oleh karena itu, arah kebijakan utama pembangunan wilayah nasional difokuskan untuk mempercepat pengurangan kesenjangan pembangunan antarwilayah.

Di berlakukannya Undang-Undang Nomor 6 Tahun 2014 tentang Desa diharapkan dapat menjadi salah satu solusi terhadap permasalahan kesenjangan antara kota dan desa. Karena tujuan dari lahirnya undang-undang ini antara lain adalah untuk memajukan perekonomian masyarakat di pedesaan, mengatasi kesenjangan pembangunan kota dan desa, memperkuat peran penduduk desa dalam pembangunan serta meningkatkan pelayanan publik bagi warga masyarakat desa.

Tahun 2015 adalah tahun pertama dilaksanakannya UU No.6 Tahun 2014 Tentang Desa. Kehadiran Kementerian Desa, Pembangunan Daerah Tertinggal, dan Transmigrasi mempunyai mandat untuk menjalankan NAWACITA Jokowi-JK, khususnya NAWACITA Ketiga yaitu 
Pengembangan Potensi Destinasi Desa Wisata Menggunakan Indeks Pembangunan Desa di Balesari Kecamatan Windusari Kabupaten Magelang

"Membangun Indonesia dari pinggiran dengan memperkuat daerah dan desa". Salah satu agenda besarnya adalah mengawal implementasi UU No 6 Tahun 2014 tentang Desa secara sistematis, konsisten dan berkelanjutan dengan fasilitasi, supervisi dan pendampingan terhadap desa dan kawasan perdesaan.

Dalam pasal 123 PP 43 tahun 2014, disebutkan bahwa: Pembangunan kawasan perdesaan merupakan perpaduan pembangunan antar desa yang dilaksanakan dalam upaya mempercepat dan meningkatkan kualitas pelayanan, pembangunan, dan pemberdayaan masyarakat Desa melalui pendekatan pembangunan partisipatif. Lebih lanjut dijelaskan bawa pembangunan kawasan perdesaan terdiri atas: a). Penyusunan rencana tata ruang kawasan perdesaan secara partisipatif; b). Pengembangan pusat pertumbuhan antar desa secara terpadu; c). Penguatan kapasitas masyarakat; d). Kelembagaan dan kemitraan ekonomi; dan e). Pembangunan infrastruktur antarperdesaan.

Balesari adalah salah satu desa yang menarik untuk dikaji potensinya sebagai salah satu destinasi wisata. Desa Balesari termasuk salah satu desa di Kecamatan Windusari yang mempunyai luas 387 ha atau sekitar 3,34 persen dari luas Kecamatan Windusari. Berdasarkan data administrasi desa, jumlah penduduk yang tercatat secara administrasi berjumlah 2.788 jiwa. Sebanyak 1.421 jiwa berjenis kelamin lakilaki, sedangkan sisanya 1.367 jiwa berjenis kelamin perempuan. Jika dilihat dari jumlah penduduk tersebut, penentuan potensi perdesaan di Desa Balesari yang meliputi identifikasi mengenai wilayah, potensi ekonomi, mobilitas penduduk, sarana dan prasarana yang mendukung pariwisata, menjadi sangat penting dilakukan untuk mempercepat dan meningkatkan kualitas pelayanan, pembangunan dan pemberdayaan masyarakat setempat. Dari latar belakang tersebut, peneliti tertarik untuk melihat potensi Desa Balesari di lihat dari indikator indeks pembangunan desa (IPD) dan indeks kemiskinan multidimensional, dan menyusun strategi dan kebijakan apa yang perlu dilakukan di Desa Balesari dalam upaya mewujudkan desa wisata.

\section{Tinjauan Pustaka}

\section{Pembangunan Desa}

Menurut Usman (2004) ada dua alasan mengapa masalah pembangunan masyarakat desa masih relevan untuk dibahas. Pertama, kendati dalam dua dasawarsa terakhir perkembangan kota maju dengan amat pesat, secara umum wilayah negara kita masih didominasi oleh daerah pedesaan. Hal ini diperkirakan masih akan berlangsung relatif lama. Benar bahwa di beberapa daerah ciri 
Bambang Kuncoro 1; Joko Tri Nugraha 2; Retno Dewi Pramodia Ahsani 3.

pedesaan itu susut perlahan bersamaan dengan

proses industrialisasi dan urbanisasi, akan tetapi itu tidak berarti hilang sama sekali. Ciri pedesaan tersebut bahkan masih akan bertahan sedemikian rupa sehingga mempengaruhi arah dan sifat perkembangan kota.

Kedua, kendati sejak awal tahun 1970 an pemerintah orde baru telah mencanangkan berbagai macam kebijakan dan program pembangunan pedesaan yang ditandai oleh inovasi teknologi modern, secara umum kondisi sosial ekonomi desa masih memprihatinkan. Betul bahwa pemerintah orde baru telah sukses menghantarkan Indonesia dari salah satu negara pengimpor beras nomor satu di dunia menjadi negara berswasembada beras dan konflik-konflik sosial yang berakar dari kompetisi memenuhi kebutuhan dasar seperti sandang, pangan dan papan serta kesehatan.

Namun demikian, persoalan kemiskinan dan kesenjangan masih menjadi masalah krusial di pedesaan. Persoalan ini tidak dapat diabaikan karena bisa menjadi pemicu berbagai konflik politik atau gerakan politik yang berkepanjangan. Karena itu, persoalan ini harus terus dicarikan alternatif pemecahannya supaya tidak menganggu stabilitas.

Sejumlah studi menunjukkan bahwa jumlah penduduk miskin dan termiskin di pedesaan masih cukup banyak. Mereka menjadi bagian dari komunitas dengan struktur dan kultur pedesaan. Kira-kira separuh dari jumlah itu benar-benar dalam kategori sangat miskin (the absolut poor). Kondisi mereka sungguh memprihatinkan, antara lain ditandai oleh malnutrition, tingkat pendidikan yang rendah (bahkan sebagian dari mereka buta huruf) dan rentan terhadap penyakit. Jumlah penghasilan dari kelompok ini hanya cukup untuk makan. Karena itu tidak mengherankan apabila perkembangan fisik dan mental mereka (termasuk anak-anaknya) juga berjalan agak lamban. Kelambanan itu terasa sekali ketika dalam kehidupan mereka diintroduksi ideologi dan teknologi baru yang berbeda dari yang sudah ada. Tidak sedikit dari mereka yang memberi respon yang negatif dan curiga.

Hiroyoshi Kano (1977) dalam penelitiannya di Malang Selatan menemukan adanya kecenderungan pemusatan pemilikan dan penguasaan tanah di tangan kelas atas dan terjadinya polarisasi penguasaan tanah di desa yang makin meruncing. Sedangkan penelitian yang dilakukan Gunawan Wiradi selama tahun 1979-1982 di sepuluh desa yang tersebar di Jawa Barat, Jawa Tengah dan Jawa Timur hasilnya kurang lebih serupa, yakni menemukan distribusi pemilikan tanah yang sangat pincang di sebagian besar desa yang diteliti. 
Untuk mengeliminasi tekanan kemiskinan yang dialaminya biasanya salah satu alternatif yang dilakukan masyarakat desa adalah pergi keluar desa. Baik dengan sukarela maupun terpaksa, sebagian warga dari daerah kelahirannya dan pergi mengadu nasib mencari pekerjaan di kota. Beberapa peneliti seperti Nasikun (1980), Mantra (1981), McGee (1982), Lloyd (1982) dan Abustam (1986) menyatakan bahwa mobilitas penduduk memang merupakan salah satu strategi yang penting bagi rumah tangga pedesaan untuk mendapatkan dan menaikkan penghasilan mereka. Gejala ini menonjol terutama pada desa-desa yang kurang maju atau desa-desa di mana kesempatan kerja yang tersedia sangat terbatas.

Hasil penelitian yang dilakukan Sinaga (1977) menemukan bahwa di desa Tukdana, Indramayu, sebuah traktor bisa membebaskan 2.210 hari orang kerja per tahun. Penelitian yang dilakukan Collier (1974) dan Nurmanaf (1980) juga menemukan gejala yang kurang lebih sama. Pendek kata, sejak adanya penetrasi bibit unggul, huller, traktor, sistem tebasan dan semacamnya telah menyebabkan semacam kesempatan kerja di desa makin berkurang sehingga banyak warga pedesaan mau tidak mau harus keluar dari sektor pertanian dan bekerja di sektor non pertanian, entah itu di sektor perdagangan tradisional dan industri kecil di pedesaan atau melakukan migrasi ke kota.

Sementara itu, Fuller (1983) menyatakan bahwa pembangunan jalan desa dalam banyak hal memang dapat meningkatkan pendapatan masyarakat pedesaan, mendorong dan memperluas komersialisasi pertanian dan mampu meningkatkan produksi pertanian. Dengan demikian, orang-orang desa akan semakin sering melakukan perjalanan ke kota dengan ongkos yang lebih murah dan lebih cepat. Dengan kalimat yang singkat Fuller menyatakan bahwa migrasi desa ke kota menjadi semakin meningkat karena integrasi desa kota semakin baik.

Akibat pendidikan warga yang pada umumnya rendah dan juga karena tidak memiliki keterampilan modern yang memadai, sering menyebabkan mereka terpaksa mencari nafkah di kota dengan melakukan usaha kecil-kecilan, menggunakan peralatan dan keterampilan sederhana yang dikuasainya. Seperti sudah dikaji oleh Todaro (1981:12) dan Tjiptoherianto (1989), kebanyakan kaum migran yang mencoba mencari perbaikan status di kota-kota besar seperti Jakarta atau Surabaya akan terserap di sektor tersier, perdagangan dan jasa yang merupakan bagian terbesar dari sektor informal di kota. Mereka bekerja sebagai pemulung, penjual keliling menggunakan pikulan atau 
Bambang Kuncoro 1; Joko Tri Nugraha 2; Retno Dewi Pramodia Ahsani 3.

gerobak dorong, pedagang asongan, pedagang

kaki lima, pengemudi becak atau pekerjaanpekerjaan lain yang umumnya merupakan bagian dari sektor informal kota (Hart, 1976; Wariso, 1990). Tidak jarang, sebagian migran kadang juga terserap pada sektor informal yang di mata hukum dipandang ilegal, sehingga mereka selalu berada dalam ancaman penertiban oleh polisi atau petugas penertiban (Wignjosoebroto, 1993).

Oleh karena itu usaha memberdayakan masyarakat desa serta menanggulangi kemiskinan dan kesenjangan menjadi fenomena yang semakin kompleks, pembangunan pedesaan dalam perkembangannya tidak semata-mata terbatas pada peningkatan produktivitas pertanian. Pembangunan pedesaan juga tidak hanya mencakup implementasi program peningkatan kesejahteraan sosial melalui distribusi uang dan jasa untuk mencukupi kebutuhan dasar. Lebih dari itu adalah sebuah upaya dengan spektrum kegiatan yang menyentuh pemenuhan berbagai macam kebutuhan sehingga segenap anggota masyarakat dapat mandiri, percaya diri, tidak bergantung dan dapat lepas dari belenggu struktural yang membuat hidup mereka sengsara.

\section{Pengembangan Kawasan Desa}

Pariwisata adalah kegiatan yang langsung menyentuh dan melibatkan masyarakat sehingga membawa berbagai dampak terhadap masyarakat setempat, bahkan pariwisata dikatakan mempunyai energi yang luar biasa yang membuat masyarakat setempat mengalami methamorphose dalam berbagai aspeknya (Sastrayuda, 2010:1).

Di samping dampak yang bernilai positif, hampir semua penelitian juga menunjukkan adanya berbagai dampak yang tidak diharapkan seperti semakin memburuknya kesenjangan pendapatan antara kelompok masyarakat, memburuknya ketimpangan ekonomi dan lain sebagainya.

Dampak-dampak negatif seperti di atas disebabkan karena pengembangan pariwisata semata-mata dlakukan dengan pendekatan ekonomi dan pariwisata dipersepsikan sebagai instrumen untuk meningkatkan pendapatan, terutama di bidang usaha swasta dan pemerintah. Sementara itu banyak pakar yang menyadari bahwa pariwisata, meskipun membutuhkan lingkungan yang baik, namun bilamana dalam pengembangannya tidak memperhatikan daya dukung lingkungan dan kerentanan lingkungan terhadap jumlah wisatawan juga akan berdampak negatif.

Sejalan dengan dinamika, gerak perkembangan pariwisata merambah dalam berbagai terminologi seperti: sustainable tourism development, village tourism, ecotourism sebagai pendekatan pengembangan pariwisata 
Pengembangan Potensi Destinasi Desa Wisata Menggunakan Indeks Pembangunan Desa di Balesari Kecamatan Windusari

Kabupaten Magelang

yang berupaya untuk menjamin agar wisata dapat dilaksanakan di daerah tujuan wisata, bukan perkotaan (Sastrayuda, 2010).

Salah satu pendekatan pengembangan wisata alternatif adalah desa wisata untuk pembangunan desa yang berkelanjutan dalam bidang pariwisata. Desa wisata adalah salah satu bentuk integrasi antara atraksi, akomodasi dan fasilitas pendukung yang disajikan dalam suatu struktur kehidupan masyarakat yang menyatu dengan tata cara dan tradisi yang berlaku. Ramuan utama desa wisata diwujudkan dalam gaya hidup dan kualitas hidup warga masyarakatnya.

Keaslian juga dipengaruhi keadaan ekonomi, fisik dan sosial daerah pedesaan misalnya ruang, warisan budaya, kegiatan pertanian, bentangan alam, jasa, pariwisata sejarah dan budaya serta pengalaman yang unik dan eksotis khas suatu daerah. Dengan demikian pemodelan desa wisata harus terus dan secara kreatif mengembangkan identitas atau ciri khas daerah.

Ramuan penting lainnya dalam pengembangan desa wisata yang berkelanjutan yaitu pelibatan atau partisipasi masyarakat setempat, pengembangan mutu produk wisata pedesaan dan pembinaan kelompok pengusaha setempat. Keaslian akan memberikan manfaat bersaing bagi produk wisata pedesaan. Unsur- unsur keaslian produk wisata yang utama adalah kualitas asli, keorisinalan, keunikan, ciri khas daerah dan kebanggaan daerah yang diwujudkan dalam gaya hidup dan kualitas hidup masyarakatnya secara khusus berkaitan dengan perilaku, integritas, keramahan dan kesungguhan penduduk yang tinggal dan berkembang menjadi milik masyarakat desa tersebut.

Menurut Nuryati (1993) terdapat dua konsep yang utama dalam desa wisata, yakni:

a. Akomodasi, yaitu sebagian dari tempat tinggal penduduk setempat dan atau unitunit yang berkembang atas tempat tinggal penduduk.

b. Atraksi, yaitu keseluruhan keseharian kehidupan penduduk setempat beserta setting fisik lokasi desa yang memungkinkan berintegrasinya wisatawan sebagai partisipasi aktif seperti kursus tari, bahasa dan lain-lain yang spesifik.

Selanjutnya beberapa pendekatan untuk pengembangan desa wisata, antara lain (UNDP dan WTO, 1981):

a. Interaksi tidak langsung

Model pengembangan didekati dengan cara bahwa desa mendapat manfaat tanpa interaksi langsung dengan wisatawan. Bentuk kegiatan yang terjadi misalnya, penulisan buku-buku tentang desa yang 
Bambang Kuncoro 1; Joko Tri Nugraha 2; Retno Dewi Pramodia Ahsani 3.

berkembang, kehidupan desa, arsitektur

tradisional, latar belakang sejarah, pembuatan kartu pos dan sebagainya.

b. Interaksi setengah langsung

Bentuk-bentuk one day trip yang dilakukan wisatawan, kegiatan-kegiatan yang meliputi makan dan kegiatan bersama penduduk dan kemudian wisatawan kemudian kembali ke tempat akomodasinya. Prinsip model tipe ini adalah bahwa wiatawan hanya singgah dan tidak tinggal bersama penduduk.

c. Interaksi langsung

Wisatawan dimungkinkan untuk tinggal dan bermalam dalam akomodasi yang ada di desa tersebut. Dampak yang terjadi dapat dikontrol dengan berbagai pertimbangan yaitu daya dukung dan potensi masyarakat setempat. Alternatif lain dari model ini adalah penggabungan dari model pertama dan model kedua.

\section{Metode Penelitian}

Metode penelitian yang digunakan adalah metode kualitatif. Penelitian ini dilakukan pada obyek yang alamiah di mana kehadiran peneliti tidak mempengaruhi dinamika pada obyek tersebut, tetapi dengan menganalisis, memotret dan mengkonstruksi situasi sosial yang diteliti menjadi lebih jelas dan bermakna (Miles dan Huberman, 2007). Penelitian ini menggunakan metode kualitatif, sementara teknik sampling yang digunakan adalah purposive sampling dan snowball sampling. Metode pengampulan data meliputi wawancara, observasi dan dokumentasi (Sugiyono, 2006). Metode analisis data yang digunakan dalam penelitian ini menggunakan teknik interaktif model analysis dari Miles and Huberman (2007), yaitu dengan data reduction, data display dan conclusion drawing serta verification.

\section{Hasil Penelitian}

Dalam mendeskripsikan variabel Indeks Pembangunan Desa (IPD) di Desa Balesari kami menggunakan lima dimensi IPD merujuk dari Kementerian Desa dan Pembangunan Daerah Tertinggal (Kemendes PDT). Lima dimensi yang kami gunakan untuk menganalisis antara lain: (1) Dimensi pelayanan dasar, yang dikaji dari dua aspek meliputi pelayanan pendidikan dan pelayanan kesehatan; (2) Dimensi kondisi infrastruktur yang dikaji dari empat aspek yaitu: infrastruktur ekonomi, infrastruktur energy, infrastruktur kesehatan dan sanitasi serta, infrastruktur komunikasi dan informasi; (3) Dimensi aksesibilitas/transportasi yang dikaji dari sarana transportasi dan aksesibilitas transportasi; (4) Dimensi pelayanan publik yang dikaji dari dua hal yang meliputi kesehatan masyarakat dan olah raga; (5) Dimensi penyelenggaraan pemerintahan yang dikaji dari 
Pengembangan Potensi Destinasi Desa Wisata Menggunakan Indeks Pembangunan Desa di Balesari Kecamatan Windusari

dua aspek yaitu kemandirian dan kualitas sumber daya manusia (SDM).

Selanjutnya untuk mendeskripsikan variabel kemiskinan multidimensional di Desa Balesari kami menggunakan beberapa dimensi pokok Indeks Kemiskinan Multidimensional (IKM), antara lain pendidikan, kesehatan serta standar kualitas hidup. Berikut adalah tabel besarnya kontribusi setiap indikator penyusun Indeks Pembangunan Desa (IPD) di Desa Balesari, Kecamatan Windusari, Kabupaten Magelang.
Tabel 1. Kontribusi Indikator Penyusun IPD di Desa Balesari 
Bambang Kuncoro 1; Joko Tri Nugraha 2; Retno Dewi Pramodia Ahsani 3.

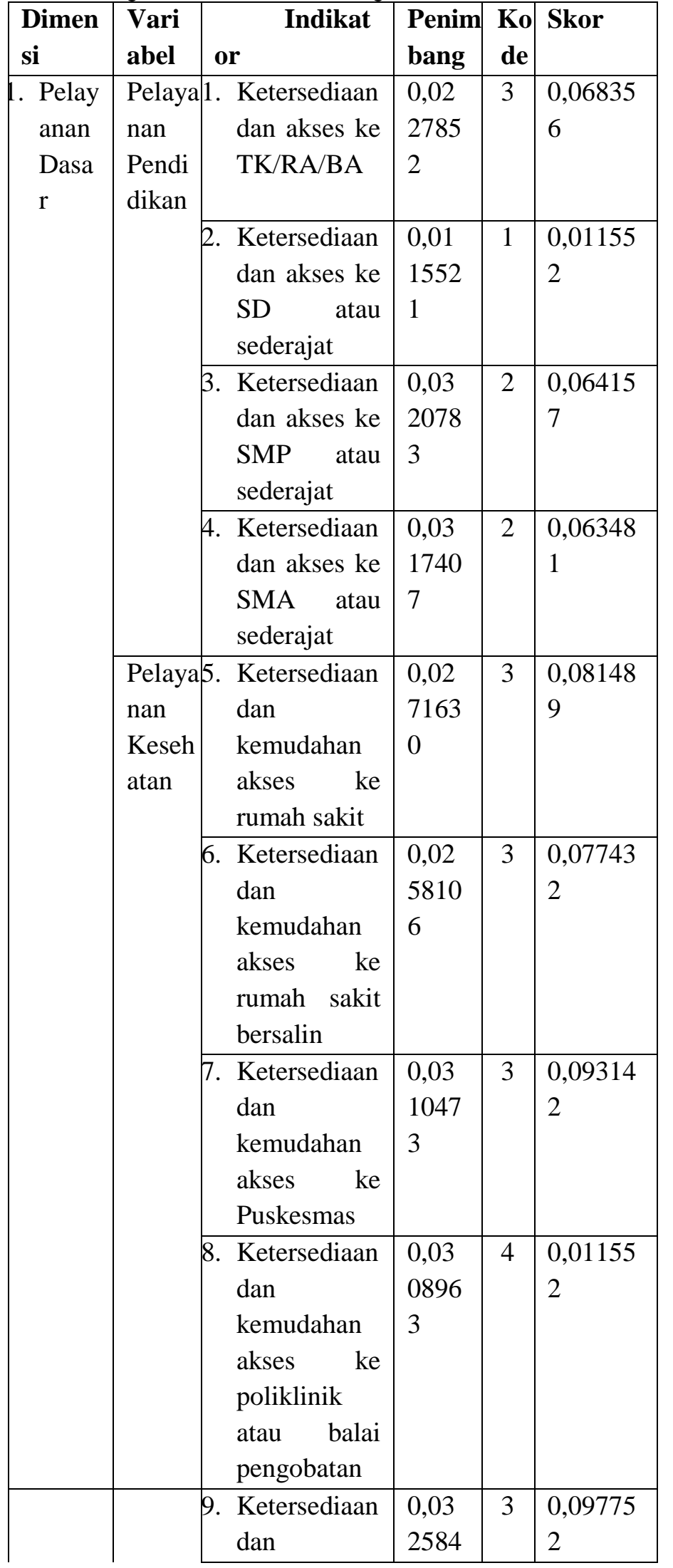

\begin{tabular}{|c|c|c|c|c|c|}
\hline $\begin{array}{l}\text { Dimen } \\
\text { si }\end{array}$ & $\begin{array}{l}\text { Vari } \\
\text { abel }\end{array}$ & $\begin{array}{l}\text { Indikat } \\
\text { or }\end{array}$ & $\begin{array}{l}\text { Penim } \\
\text { bang }\end{array}$ & $\begin{array}{l}\text { Ko } \\
\text { de }\end{array}$ & Skor \\
\hline & & $\begin{array}{l}\text { kemudahan } \\
\text { akses ke } \\
\text { tempat } \\
\text { praktek } \\
\text { dokter }\end{array}$ & 1 & & \\
\hline & & \begin{tabular}{|l} 
10. Ketersediaan \\
dan \\
kemudahan \\
akses ke \\
tempat \\
praktek \\
bidan
\end{tabular} & $\begin{array}{l}0,02 \\
9933 \\
8\end{array}$ & 4 & $\begin{array}{l}0,11973 \\
5\end{array}$ \\
\hline & & $\begin{array}{l}\text { 11. Ketersediaan } \\
\text { dan } \\
\text { kemudahan } \\
\text { akses ke } \\
\text { Poskesdes } \\
\text { atau } \\
\text { polindes }\end{array}$ & $\begin{array}{l}0,02 \\
5211 \\
1\end{array}$ & 1 & $\begin{array}{l}0,02521 \\
1\end{array}$ \\
\hline & & $\begin{array}{l}\text { 12. Ketersediaan } \\
\text { dan } \\
\text { kemudahan } \\
\text { akses ke } \\
\text { apotik }\end{array}$ & $\begin{array}{l}0,02 \\
5356 \\
6\end{array}$ & 1 & $\begin{array}{l}0,02535 \\
7\end{array}$ \\
\hline \multirow[t]{2}{*}{$\begin{array}{l}\text { Kond } \\
\text { isi } \\
\text { Infra } \\
\text { struk } \\
\text { tur }\end{array}$} & \multirow{2}{*}{$\begin{array}{l}\text { Infrast } \\
\text { ruk tur } \\
\text { Ekono } \\
\mathrm{mi}\end{array}$} & $\begin{array}{l}\text { 13. Ketersediaan } \\
\text { mini market, } \\
\text { pertokoan } \\
\text { atau toko } \\
\text { kelontong }\end{array}$ & $\begin{array}{l}0,01 \\
9616 \\
5\end{array}$ & 2 & $\begin{array}{l}0,03923 \\
3\end{array}$ \\
\hline & & $\begin{array}{l}\text { 14. Ketersediaan } \\
\text { pasar }\end{array}$ & $\begin{array}{l}0,01 \\
7977 \\
3\end{array}$ & 2 & $\begin{array}{l}0,03595 \\
5\end{array}$ \\
\hline
\end{tabular}

Sumber: Data Primer Diolah, 2018

Dari perhitungan tabel 1 di atas mengenai kontribusi penyusunan variabel IPD Desa Balesari maka dapat dihitung IPD Desa Balesari dengan menggunakan formulasi sebagai berikut: IPD $=$

$$
\begin{gathered}
\left(\mathrm{V}_{1} * \mathrm{~B}_{1}+\mathrm{V}_{2} * \mathrm{~B}_{2}+\mathrm{V}_{3} * \mathrm{~B}_{3} \ldots+\mathrm{V}_{42} * \mathrm{~B}_{42}\right) * 20 \\
\mathrm{IPD}=(2,43606 \times 20)
\end{gathered}
$$


IPD $=48,72119$

Mendasarkan pada penghitungan Indeks Pembangunan Desa, Desa Balesari masuk ke dalam klasifikasi terakhir yaitu desa tertinggal artinya desa yang mempunyai ketersediaan dan akses terhadap pelayanan dasar, infrastruktur, aksesibilitas atau transportasi, pelayanan publik dan penyelenggaraan pemerintahan yang masih minim. Pada teknisnya desa tertinggal merupakan desa dengan nilai IPD kurang dari sama dengan 50 .

\section{Kesimpulan}

1. Perlu dilakukan penelitian lebih lanjut mengenai potensi wisata dan potensi kearifan lokal yang ada di desa Balesari.

2. Hasil penghitungan potensi desa Balesari menggunakan Indeks Pembangunan Desa (IPD) adalah sebesar 48,72119 artinya desa yang mempunyai ketersediaan dan akses terhadap pelayanan dasar, infrastruktur, aksesibilitas atau transportasi, pelayanan publik dan penyelenggaraan pemerintahan yang masih minim.

3. Kebijakan pemerintah daerah dalam mengontrol pengembangan desa wisata di Desa Balesari belum ada.

4. Kegiatan masyarakat sehari-hari dalam bertani atau berkebun salak serta memelihara ternak dapat dikemas menjadi salah satu atraksi wisata yang menarik.

5. Dukungan dan keterlibatan peran tokoh masyarakat Desa Balesari dalam pengembangan menjadi desa wisata masih kurang

\section{Rekomendasi Kebijakan}

Rekomendasi untuk Pemkab Magelang
1. Agar Balesari menjadi salah satu desa wisata, maka perlu dibuat peraturan atau kebijakan pemerintah yang mengatur proses pengembangannya.

2. Perlu adanya sinergi kebijakan antara dinas pariwisata dan pemerintah desa.

\section{Rekomendasi untuk Pemerintah Desa}

\section{Balesari}

1. Perangkat desa perlu segera melakukan musrenbangdes agar harapan warga masyarakat Desa Balesari menjadi desa wisata dapat terakomodir dan terencana dengan baik.

2. Perangkat desa perlu menumbuhkan partisipasi masyarakat dan tokoh setempat agar berperan aktif dalam pengembangan desa wisata Balesari.

3. Perangkat desa perlu meningkatkan kualitas sumber daya manusia dengan cara melakukan pelatihan, menambah wawasan tentang pariwisata dan cara memperlakukan wisatawan sebagai persiapan awal pengembangan desa wisata Balesari 
Bambang Kuncoro 1; Joko Tri Nugraha 2; Retno Dewi Pramodia Ahsani 3.

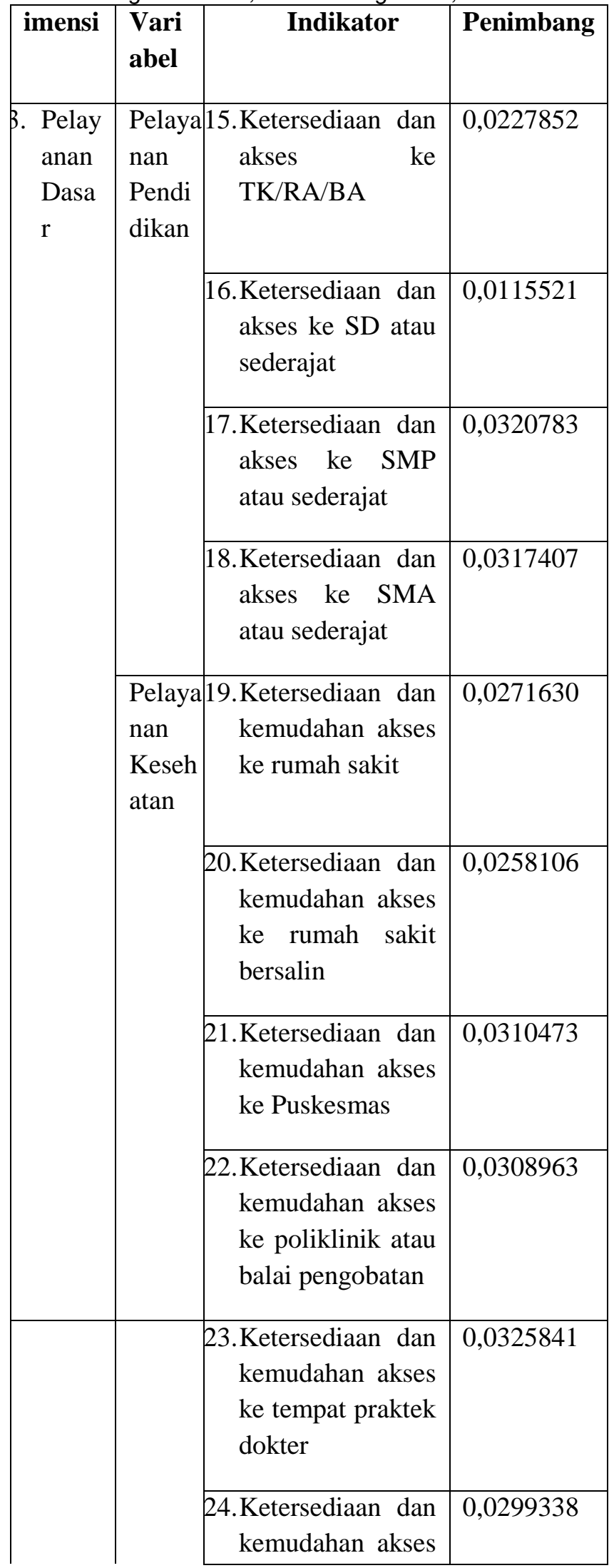

\begin{tabular}{|c|c|c|c|}
\hline imensi & $\begin{array}{l}\text { Vari } \\
\text { abel }\end{array}$ & Indikator & Penimbang \\
\hline & & $\begin{array}{l}\text { ke tempat praktek } \\
\text { bidan }\end{array}$ & \\
\hline & & $\begin{array}{l}\text { 25. Ketersediaan dan } \\
\text { kemudahan akses } \\
\text { ke Poskesdes atau } \\
\text { polindes }\end{array}$ & 0,0252111 \\
\hline & & $\begin{array}{l}\text { 26. Ketersediaan dan } \\
\text { kemudahan akses } \\
\text { ke apotik }\end{array}$ & 0,0253566 \\
\hline \begin{tabular}{|l} 
4. Kond \\
isi \\
Infra \\
struk \\
tur
\end{tabular} & $\begin{array}{l}\text { Infrast } \\
\text { ruk tur } \\
\text { Ekono } \\
\text { mi }\end{array}$ & $\begin{array}{l}\text { 27. Ketersediaan } \\
\text { mini market, } \\
\text { pertokoan atau } \\
\text { toko kelontong }\end{array}$ & 0,0196165 \\
\hline & & $\begin{array}{l}\text { 28. Ketersediaan } \\
\text { pasar }\end{array}$ & 0,0179773 \\
\hline & & \begin{tabular}{|l} 
29. Ketersediaan \\
restoran, rumah \\
makan atau \\
warung/kedai \\
makanan
\end{tabular} & 0,0152138 \\
\hline & & $\begin{array}{c}\text { 30. Ketersediaan } \\
\text { akomodasi hotel } \\
\text { atau penginapan }\end{array}$ & 0,0186228 \\
\hline & & $\begin{array}{l}\text { 31. Ketersediaan } \\
\text { bank }\end{array}$ & 0,0029853 \\
\hline & $\begin{array}{l}\text { Infrast } \\
\text { ruk tur } \\
\text { Energi }\end{array}$ & 32.Elektrifikasi & 0,0140417 \\
\hline & & $\begin{array}{l}\text { 33. Kondisi } \\
\text { penerangan di } \\
\text { jalan utama }\end{array}$ & 0,0188277 \\
\hline
\end{tabular}


Pengembangan Potensi Destinasi Desa Wisata Menggunakan Indeks Pembangunan Desa di Balesari Kecamatan Windusari

\begin{tabular}{|c|c|c|c|}
\hline imensi & $\begin{array}{l}\text { Vari } \\
\text { abel }\end{array}$ & Indikator & Penimbang \\
\hline & & $\begin{array}{c}\text { 34.Bahan bakar } \\
\text { untuk memasak }\end{array}$ & 0,0177782 \\
\hline & $\begin{array}{l}\text { Infrast } \\
\text { ruk tur } \\
\text { Keseh } \\
\text { atan } \\
\text { dan } \\
\text { Sanita } \\
\text { si }\end{array}$ & $\begin{array}{l}\text { 35.Sumber air untuk } \\
\text { minum }\end{array}$ & 0,0299481 \\
\hline & & $\begin{array}{l}\text { 36. Sumber air untuk } \\
\text { mandi/cuci }\end{array}$ & 0,0301380 \\
\hline & & $\begin{array}{l}\text { 37.Fasilitas buang } \\
\text { air besar }\end{array}$ & 0,0137127 \\
\hline & $\begin{array}{l}\text { Infrast } \\
\text { ruk tur } \\
\text { Infor } \\
\text { masi } \\
\text { dan } \\
\text { Komu } \\
\text { nika si }\end{array}$ & $\begin{array}{l}\text { 38. Ketersediaan dan } \\
\text { kualitas fasilitas } \\
\text { komunikasi } \\
\text { seluler }\end{array}$ & 0,0160403 \\
\hline & & $\begin{array}{l}\text { 39. Ketersediaan } \\
\text { fasilitas internet } \\
\text { dan pos serta } \\
\text { pengiriman } \\
\text { barang }\end{array}$ & 0,0172964 \\
\hline $\begin{array}{l}\text { Akse } \\
\text { sibili } \\
\text { tas } \\
\text { atau } \\
\text { Tran } \\
\text { sport } \\
\text { asi }\end{array}$ & $\begin{array}{l}\text { Sarana } \\
\text { Trans } \\
\text { portasi }\end{array}$ & $\begin{array}{l}\text { 40.Lalu lintas dan } \\
\text { kualitas jalan }\end{array}$ & 0,0174274 \\
\hline & & $\begin{array}{l}\text { 41. Aksesibilitas } \\
\text { jalan }\end{array}$ & 0,0149853 \\
\hline
\end{tabular}

Kabupaten Magelang

\begin{tabular}{|c|c|c|c|}
\hline imensi & $\begin{array}{l}\text { Vari } \\
\text { abel }\end{array}$ & Indikator & Penimbang \\
\hline & & $\begin{array}{l}\text { 42. Ketersediaan } \\
\text { angkutan umum }\end{array}$ & 0,0426582 \\
\hline & & $\begin{array}{l}\text { 43. Operasional } \\
\text { angkutan umum }\end{array}$ & 0,0422595 \\
\hline & $\begin{array}{l}\text { Aksesi } \\
\text { bili tas } \\
\text { Trans } \\
\text { portasi }\end{array}$ & $\begin{array}{l}\text { 44. Waktu tempuh } \\
\text { per kilometer } \\
\text { transportasi ke } \\
\text { Kantor Camat }\end{array}$ & 0,0177129 \\
\hline & & \begin{tabular}{|ll} 
45. Biaya & per \\
kilometer & \\
transportasi & ke \\
Kantor Camat &
\end{tabular} & 0,0280166 \\
\hline & & $\begin{array}{l}\text { 46. Waktu tempuh } \\
\text { per kilometer } \\
\text { transportasi ke } \\
\text { Kantor } \\
\text { Bupati/Walikota }\end{array}$ & 0,0142172 \\
\hline & & $\begin{array}{ll}\text { 47. Biaya } & \text { per } \\
\text { kilometer } & \\
\text { transportasi } & \text { ke } \\
\text { Kantor } & \\
\text { Bupati/Walikota }\end{array}$ & 0,0264609 \\
\hline \multirow[t]{4}{*}{$\begin{array}{l}\text { 5. Pelay } \\
\text { anan } \\
\text { Publi } \\
\text { k }\end{array}$} & \multirow[t]{2}{*}{$\begin{array}{l}\text { Keseh } \\
\text { atan } \\
\text { Masya } \\
\text { ra kat }\end{array}$} & $\begin{array}{l}\text { 48.Penanganan } \\
\text { Kejadian Luar } \\
\text { Biasa (KLB) }\end{array}$ & 0,0195116 \\
\hline & & $\begin{array}{l}\text { 49.Penanganan gizi } \\
\text { buruk }\end{array}$ & 0,0209339 \\
\hline & \multirow[t]{2}{*}{$\begin{array}{l}\text { Olah } \\
\text { Raga }\end{array}$} & $\begin{array}{l}\text { 50. Ketersediaan } \\
\text { fasilitas olah raga }\end{array}$ & 0,0334978 \\
\hline & & $\begin{array}{l}\text { 51. Keberadaan } \\
\text { kelompok olah }\end{array}$ & 0,0351981 \\
\hline
\end{tabular}


Bambang Kuncoro 1; Joko Tri Nugraha 2; Retno Dewi Pramodia Ahsani 3.

\begin{tabular}{|c|c|c|c|}
\hline imensi & $\begin{array}{l}\text { Vari } \\
\text { abel }\end{array}$ & Indikator & Penimbang \\
\hline & & raga & \\
\hline \multirow[t]{5}{*}{$\begin{array}{l}\text { Peny } \\
\text { eleng } \\
\text { garaa } \\
\mathrm{n} \\
\text { Peme } \\
\text { rinta } \\
\text { han }\end{array}$} & \multirow[t]{3}{*}{$\begin{array}{l}\text { Kema } \\
\text { ndi } \\
\text { rian }\end{array}$} & $\begin{array}{l}\text { 52. Kelengkapan } \\
\text { pemerintahan } \\
\text { desa }\end{array}$ & 0,0260184 \\
\hline & & 53.Otonomi desa & 0,0163094 \\
\hline & & $\begin{array}{c}\text { 54. Aset atau } \\
\text { kekayaan desa }\end{array}$ & 0,0198562 \\
\hline & \multirow[t]{2}{*}{$\begin{array}{l}\text { Kualit } \\
\text { as } \\
\text { Sumb } \\
\text { er } \\
\text { Daya } \\
\text { Manus } \\
\text { ia }\end{array}$} & $\begin{array}{l}\text { 55.Kualitas SDM } \\
\text { Kepala Desa }\end{array}$ & 0,0186415 \\
\hline & & $\begin{array}{c}\text { 56. Kualitas SDM } \\
\text { Sekretaris Desa }\end{array}$ & 0,0279371 \\
\hline \multicolumn{4}{|l|}{$\begin{array}{l}\text { Skor } \\
\text { Total }\end{array}$} \\
\hline
\end{tabular}

\section{Daftar Pustaka}

Abustam, Muhammad Idrus. 1989. Gerak Penduduk, Pembangunan dan Perubahan Sosial, Kasus Tiga Komunitas Padi Sawah di Sulawesi Selatan. Jakarta: UI Press.

Agusta, Ivanovich. 2015. Pemerintah Daerah dan Desa. Kompas 12 Oktober.

Bach, Wendy A. 2010. Governance, Accountability and the New Poverty Agenda, Wisconsin Law Review 2010 No. 2 239-356 2010.

Bryant, Coralie and White, Louise G. 1982. Managing Development in The Third World, Westiew Press, Boulder, Colorado.

Hadi, Sutrisno. 1985. Metodologi Research Untuk Paper, Skripsi, Thesis dan Disertasi, Jilid I Cetakan Ke XVII. Yogyakarta:Yayasan Penerbit Fakultas Psikologi, Universitas Gadjah Mada.

, 1986. Metodologi Research Untuk Paper, Skripsi, Thesis dan Disertasi, Jilid IV Cetakan Ke III, Yogyakarta:Yayasan Penerbit Fakultas Psikologi, Universitas Gadjah Mada.

Iryanto. 2006. Perencanaan Pembangunan Kabupaten/Kota Melalui Pendekatan Wilayah dan Kerjasama Antar Daerah, Jurnal Perencanaan dan Pengembangan Wilayah Wahana Hijau, Volume 1, Nomor 3, April 2006.

Melish, Tara J. 2010. Maximum Feasible Participation of the Poor: New Governance, New Accountability, and a 21 (supst) Century War on the Source of Poverty, Yale Human Rights\&Development Law Journal 13 1-33 2010.

Miles, Matthew, B. And A. Michael Huberman. 1992. Qualitative Data Analysis. Sage Publications, Inc.

Muller, Johannes. 2006. Perkembangan Masyarakat Lintas Ilmu. Jakarta: Gramedia Pustaka Utama. 
Pengembangan Potensi Destinasi Desa Wisata Menggunakan Indeks Pembangunan Desa di Balesari Kecamatan Windusari

Kabupaten Magelang

Ndraha, Taliziduhu. 1990. Pembangunan Masyarakat Mempersiapkan Masyarakat Tinggal Landas. Jakarta: Rineka Cipta.

Mantra, Ida Bagus. 1991. Mobilitas Penduduk Sirkuler Dari Desa ke Kota di Indonesia. Yogyakarta: Pusat Penelitian Kependudukan UGM.

Malik, Hermen. Pengeloaan Keberagaman Menuju Desa Berdaulat. 2015. Pemerintah Kabupaten Kaur, Provinsi Bengkulu.

Marsoyo, Agam. 2015. Draf Peraturan Menteri tentang Pembangunan Kawasan Perdesaan. Pusat Studi Perencanaan Perencanaan Pembanguna Regional, Universitas Gadjah Mada.

Miles, Mattew B. dan A. Michael Huberman. 2007. Analisis Data Kualitatif Buku Tentang Sumber Metode-Metode Baru. Jakarta: UI Press.

Mirasa, Bachtiar Hasan. 2005. Perencanaan dan Pengembangan Wilayah. Bandung: ISEI.

Nuryati, Wiendu. 1993. Concept, Perspektive and Challenges. Makalah Bagian dari Laporan Konferensi Internasional Mengenai Pariwisata Budaya. Yogyakarta: Gadjah Mada University Press.

Peraturan Pemerintah No. 45 Tentang Desa.

Peraturan Pemerintah No. 60 tahun 2014 Tentang Dana Desa yang Bersumber dari Aanggaran Pendapatan dan Belanja Negara.

Prabatmodjo, Hastu. 2015. Sosialisasi Pembangunan Kawasan Perdesaan. Kelompok Keahlian Perencanaan Wilayah dan Perdesaan Sekolah Arsitektur, Perencanan dan Pengembangan Kebijakan, Institut Teknologi Bandung.

Sastrayudha, Gumelar. S. 2010. Handout Mata Kuliah Concept Resort And Leisure, Strategi Pengembangan dan Pengelolaan Resort and Leisure.
Slamet. Y. 1994. Pembangunan Masyarakat Berwawasan Partisipasi. Surakarta: Sebelas Maret University Press.

Sugiyono . 2006. Metode Penelitian Administrasi. Bandung: Alfabeta.

Sugiyono. 2008. Metode Penelitian Kuantitatif, Kualitatif dan R\&D. Bandung: Alfabeta.

Tjokroamidjojo, Bintoro dan Mustopadidjaja. 1984. Teori dan Strategi Pembangunan Nasional. Jakarta: Gunung Agung.

, 1996. Kebijaksanaan Dan Administrasi Pembangunan, Perkembangan Teori Dan Penerapan. Jakarta: LP3ES.

- 1999. Pengantar Administrasi Pembangunan. Jakarta: LP3ES.

Usman, Sunyoto. 2004. Pembangunan dan Pemberdayaan Masyarakat. Yogyakarta: Pustaka Pelajar.

UNDP dan WTO. 1981. Tourism Development Plan For Nusa Tenggara Indonesia, Madrid: World Tourism Organization.

Undang-Undang No. 6 Tahun 2014 Tentang Desa.

UU Nomor 23 Tahun 2014 tentang Pemerintahan Daerah.

Wirosardjono, Soetjipto. 1993. Pengentasan Kemiskinan dan Statistik dalam: Seri Kajian Fiskal dan Moneter No. 6, Strategi Perencanaan dan Evaluasi Pengentasan Kemiskinan, LFMS, Jakarta.

Wignjosoebroto, Soetandyo dkk., 1994. Problem Pemasaran dan Mekanisme Survival Petani Garam di Pulau Madura, Lembaga Penelitian Unair dan DP3M, Surabaya.

Wirawan, I.B. 1994. Mekanisme Survival dan Pola Remmitance Migran Sirkuler di Kotamadya Surabaya, Lembaga Penelitian Unair dan DP3M. 


\section{Biodata Setiap Penulis}

Dr. Bambang Kuncoro, M.Si (Dosen Prodi Ilmu Administrasi Negara, Fakultas Ilmu Sosial dan Ilmu Politik, Universitas Tidar. Lahir di Sukoharjo, 4 Oktober 1956. Mata kuliah yang diampu antara lain MPS Kualitatif dan Issue dan Kebijakan Otda, HP. 085869931829).

Joko Tri Nugraha, S.Sos, M.Si (Dosen Prodi Ilmu Administrasi Negara, Fakultas Ilmu Sosial dan Ilmu Politik, Universitas Tidar. Lahir di Sleman, 9 Juni 1981. Mata kuliah yang diampu antara lain Pengantar Statistik dan Kebijakan Publik, HP. 081327039155). Anggota ASIAN sejak 2012.

Retno Dewi Pramodia Ahsani, S.IP, MPA (Dosen Prodi Ilmu Administrasi Negara, Fakultas Ilmu Sosial dan Ilmu Politik, Universitas Tidar. Lahir di Magelang, 14 Juni 1990. Mata kuliah yang diampu antara lain Pengantar Ilmu Administrasi Negara dan Manajemen Pelayanan Publik, HP. 0811260873). 